\title{
MIS CITAS CON VICO
}

\section{José Villalobos \\ (Real Academia Sevillana de Buenas Letras)}

RESUMEN: El Autor rememora, estructurado en cuatro encuentros internacionales o "citas con Vico", su interés y acercamiento a Vico, fruto de una casualidad. Vico ha significado un referente en el proceso continuado que el Autor despliega desde hace décadas en sus tareas y empeños filosóficos de elaborar una filosofía de la razón radical frente a la razón racionalista, de una "razón diligente" frente a la "razón perezosa" y, en definitiva, del "filósofo creador" frente al "pantólogo".

Palabras ClaVe: Vico, $350^{\circ}$ Aniversario, razón radical, filósofo-creador, pantólogo, "Centro de Investigaciones sobre Vico", Cuadernos sobre Vico, J.M. Sevilla, M. Pastor, J. Villalobos.

\section{My meetings with Vico}

ABSTRACT: The Author recalls, structured in four international meetings or "dates with Vico", his interest and approach to Vico, the result of a coincidence. Vico has been a reference for the Author along decades in his ongoing endeavors and philosophical efforts to develop a philosophy of radical reason against rationalist reason, of "diligent reason" versus "lazy reason" and, in short, of the "creative philosopher" versus the "pantologist".

KEYWORDS: Vico, $350^{\text {th }}$ Anniversary, radical reason, philosopher-creator, pantologist, "Centro de Investigaciones sobre Vico", Cuadernos sobre Vico, J.M. Sevilla, M. Pastor, J. Villalobos.

\section{I miei incontri con Vico}

RIASSUNTO: L'Autore rievoca, strutturando il contributo in quattro incontri internazionali o "appuntamenti con Vico", il proprio interesse e il proprio approccio a Vico, che, di fatto, è frutto di una coincidenza. Vico ha significato un riferimento nel processo che l'Autore impiega da decenni nei suoi lavori e nel suo impegno filosofico al fine di sviluppare una filosofia della ragione radicale contrapposta alla ragione razionalista, una filosofia della "ragione diligente" contro "la ragione pigra" e , in breve, la figura di "filosofo creativo" contro quella di "pantologo".

PARole ChiAVE: Vico, $350^{\circ}$ Anniversario, ragione radicale, filosofo-creatore, pantologo, "Centro de Investigaciones sobre Vico", Cuadernos sobre Vico, J.M. Sevilla, M. Pastor, J. Villalobos.

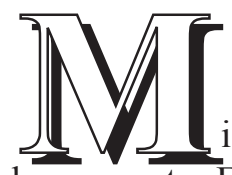

i encuentro con Vico comenzó el día aquel en que un recién licenciado en nuestra Facultad de Filosofía, José Manuel Sevilla Fernández, acudió a mí para que le dirigiera su trabajo final de Licenciatura (llamado de modo coloquial "tesina") sobre Vico; investigación presentada en 1982 con el título de $L a$ interpretación del hombre y de la historia en Vico, y que recibió la máxima califica- 
ción. Hasta ese momento, desgraciadamente, no había dedicado una especial atención a Vico ni en mis investigaciones ni en mis clases de Historia de la Filosofía o de Metafísica. Sin embargo, aceptar su dirección fue el momento de leer, conocer y apreciar al pensador napolitano. Los comentarios sobre el trabajo y las críticas sobre su redacción fueron la ocasión propicia para interesarme por dicho pensador.

Después J.M. Sevilla me ofreció dirigirle su Tesis de Doctorado, que trataría sobre el mismo pensador; Tesis que fue presentada y defendida en 1987 en nuestra Facultad de Filosofía con el título de La metafisica de la mente humana y el historicismo antropológico viquiano, obteniendo la calificación de sobresaliente cum laude.

Durante los años de investigación seria y constante de J.M.Sevilla, no tengo duda de los avances de contenido y metodológicos que realizó; y también fueron muy fructíferos para ampliar mi conocimiento sobre Vico y comprender la actualidad de este pensador en la Historia de la Filosofía Occidental así como el puesto relevante que ha de ocupar en ella.

Mi primera cita filosófica con Vico tuvo lugar con ocasión de la publicación del primer número de la Revista Cuadernos sobre Vico en 1991, que se iba a lanzar por iniciativa del Prof. Sevilla y del Prof. Miguel Pastor. Ellos me incitaron a que mi colaboración tratase de la relación de Donoso Cortés con Vico, y acepté de buen grado el encargo. Me refiero a mi artículo El hacha niveladora: Donoso Cortés y Vico.

La aportación donosiana al conocimiento de Vico en España es de las primeras, y fueron una serie de artículos periodísticos con el título de Filosofía de la Historia. Juan Bautista Vico (en 1838). La rigurosa temática de la Filosofía de la Historia de Vico permitía, por primera vez, la distinción entre mundo de la naturaleza y mundo civil; y Donoso Cortés es consciente de su novedad, y por eso inicia su divulgación en España. La recepción viquiana tiene para Donoso una perspectiva teórica (a saber, «descubrir la naturaleza interna de las cosas»), pero también tiene un interés pragmático: difundir las doctrinas de Vico y que sea conocido en el mundo cultural español. Como el poder de la política influye en el quehacer filosófico, dice Donoso que los políticos actúan como «hacha niveladora» sobre la Filosofía en el mundo cultural español, y reconoce en el pensamiento de Vico un arma poderosa para combatir sus perversos efectos.

Otras colaboraciones siguieron a esta primera en la misma Revista; entre otras contribuciones viquianas están la traducción del francés del artículo de Jorge Uscatescu «Actualidad y perennidad de Vico» (1993), Luces cristianas y fuentes viquianas (2010), que es una reseña del libro de Antonio Sabetta, y, por último, la reedición revisada en el número anterior extraordinario (2017) de mi texto Vico ensayador, original de una ponencia italiana en 1999.

Fui invitado a participar en las Giornate Internazionali di Studi: Simbolo, Metafora e Linguaggio, a celebrar en Sansepolcro y Anghiari en abril de 1996. Aproveché esta segunda cita con Vico para escribir una ponencia titulada Povera 
e nuda vai, filosofia. Pretendió ser una reflexión sobre la situación actual de la filosofía; y ante esta crisis de la misma reivindiqué el esfuerzo para que pudiese ser expresada en sistema para llegar, de este modo, a la comprensión intersubjetiva de la verdad de la "cosa misma". De esta forma nos estábamos enfrentando al fragmentarismo filosófico de mera palabrería, que rezuma el cansancio en buscar la verdad. La primera postura fue llamada «razón diligente» y la segunda «razón perezosa».

También estudié la «razón radical» frente a la «razón racionalista». Descartes puede ser señalado como modelo de la "modernidad", que se expresa en un sistema abstracto de "ordo et mensura". Frente a esto hablamos de la "época radical», en que se ejerce una razón que abarca todos los elementos racionales (no sólo intelectivos o racionales, sino también la acción y los sentimientos). En la época radical debe ser usada la «razón diligente», y Vico, con su modelo de razón más amplia y abierta, podría ser el colaborador pertinente en la superación de la crisis actual de la Filosofía.

Vico supera, técnicamente, la razón racionalista, reductora que se aleja de la vida, y ejerce una razón que -integrando el mundo físico- incide sobre todo en el mundo humano.

En las siguientes Giornate Internazionali di Studi: Il mondo de Vico / Vico nel mondo, celebradas en Roma y Sansepolcro en abril de 1999, presenté la ponencia titulada Vico, ensayador. En esta ocasión quise destacar otro aspecto o cualidad de la «razón diligente»: que es tentativa, ensayadora; asume el riesgo de equivocación en su búsqueda de la verdad. Actúa como el «ensayador» y por eso es humilde y comedida. Por el contrario, la «razón perezosa» da por definitiva cualquier verdad, pues todo es relativo: se muestra arrogante y presuntuosa.

Utilicé a Vico como el filósofo que analiza los problemas filosóficos como con una balanza de precisión («saggiatore» en Galileo); no puede conocer toda la verdad, pero sí puede acercarse, intentarlo, en una palabra: "ensayarlo". Ese es el modo filosófico viquiano de ver las cosas. De ahí partió mi división y categorización del canon filosófico entre filósofos «ensayadores» y "pantólogos», pues pensamos que hoy día la lucha filosófica se libra entre una y otra actitud.

Mi última cita con Vico fue en el Congreso Internacional Pensar para el nuevo siglo: Giambattista Vico y la Cultura Europea, celebrado en Sevilla en octubre de 1999, donde presenté mi ponencia La mirada y la creación. Dicho título alude a la actitud originaria y propia de la filosofía: la mirada creadora solo se posee «retornando al origen». Se muestra que Vico es un modelo necesario de esa vuelta al origen en el siglo XXI.

La filosofía es una mirada cautivada por las cosas. En efecto, las cosas nos llaman y nos reclaman: los griegos hablan de "filozeamones" (los amigos del mirar). Vico afirma, como es conocido, que se puede conocer el mundo civil porque lo hemos 
hecho y por ello podemos saber de él. Además, la filosofía debe ser creadora, ya que la filosofía es "recordar" (un re-crear) lo ya conocido de modo innovador.

¿Cómo crea la filosofía? La creación noética-la filosofía-tiene semejanza con la creación poiética. ¿Es ratio o inventio?: ambas posiciones son complementarias. Vico es un pensador que tiene presentes los orígenes, los principios; Vico, pues, estudia la tradición humanista (Grassi). La razón humanista o ingeniosa rompe los límites de la razón, y por ello la razón radical abarca ambos modos de razón, es razón diligente.

Para concluir he de referir mi participación, como colaborador, en la publicación de la Revista Cuadernos sobre Vico y en la creación del "Centro de Investigaciones sobre Vico" en 1991. Ambas empresas filosóficas fueron puestas en marcha y desarrollada de modo ejemplar y dinámico por los profesores Sevilla y Pastor en el marco del Departamento de Metafísica y Corrientes Actuales de la Filosofía, de la Facultad de Filosofía de la Universidad de Sevilla. En aquel entonces yo ocupaba la Dirección de dicho Departamento. Los dos profesores promotores me permitieron ayudar en la puesta en marcha de ambas empresas filosóficas.

Los Cuadernos sobre Vico han logrado publicarse desde 1991 hasta hoy día, lo que es una hazaña en los tiempos que corren en nuestro país con las publicaciones filosóficas. Esta revista ha ofrecido al estudioso viquiano la información necesaria de las investigaciones sobre Vico en España, Italia, Hispanoamérica y otros países. Por otra parte, está abierta a todo tipo de colaboraciones, sin acepción de personas, admitiendo las nuevas orientaciones surgidas sobre el pensamiento viquiano. A destacar el que cuenta con un prestigio a nivel internacional, debido a la calidad y variedad de sus aportaciones.

Paralelamente a la Revista fue fundado el "Centro de Investigaciones sobre Vico" por los dos mismos profesores antes citados, contando, como se ha dicho, con la colaboración del Departamento de Metafísica y Corrientes Actuales de la Filosofía. Este Centro mantiene sus tareas, a pesar de los escaso medios económicos que pudo encontrar para su desarrollo activo. Podríamos señalar la realización de seminarios y conferencias, la promoción de pensamiento viquiano en trabajos doctorales, y la estancia de algunos investigadores nacionales y extranjeros que han requerido su uso. Entre esas actividades es de destacar, por la dimensión mundial y volumen humano que tuvo, la preparación y ejecución del Congreso Internacional Pensar para el nuevo siglo: Giambattista y la Cultura Europea, que tuvo lugar en Sevilla del 4 al 9 de octubre de 1999; y, desde luego, la edición de la Revista, que es el proyecto fundamental y básico del Centro.

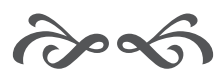

